\title{
Yttrium Y 90 DOTA Anti-CEA Monoclonal Antibody M5A
}

National Cancer Institute

\section{Source}

National Cancer Institute. Yttrium Y 90 DOTA Anti-CEA Monoclonal Antibody M5A. NCI

Thesaurus. Code C77853.

A radioimmunoconjug ate consisting of a monoclonal antibody directed against the human carcinoembryonic antigen (CEA) conjug ated with the radioisotope yttrium 90 (Y90) via the chelator tetra-azacyclododecanetetra-acetic acid (DOTA) with potential antineoplastic activity. The antibody moiety of yttrium Y 90 DOTA anti-CEA monoclonal antibody M5A binds to cells expressing the CEA antigen. Upon cellular internalization, this agent selectively delivers a cytotoxic dose of beta radiation. CEA, a tumor associated antigen, is overexpressed in many cancer types, including gastrointestinal, breast, nonsmall cell lung, and thyroid cancers. 